\title{
Comparative study of plasma zinc and selenium levels amongst Human Immunodeficiency Virus(HIV) positive and negative subjects
}

\author{
Nwegbu Maxwell Madueke', Egua Maxwell Osaronowen², Ogwu Okpanachi Samuel ${ }^{3}$ \\ ${ }^{1}$ Department of Chemical Pathology, College of Health Sciences, University of Abuja, Abuja, \\ Nigeria. \\ ${ }^{2}$ Department of Pharmacology, College of Health Sciences, University of Abuja, Abuja, Nigeria. \\ ${ }^{3}$ College of Health Sciences, University of Abuja. \\ Corresponding Author Email:maxwellnwegbu@gmail.com
}

\begin{abstract}
The study was a comparative evaluation of plasma levels of selenium and zinc trace elements amongst HIV-positive and HIV-negative apparently healthy, individuals. The comparative cross sectional study comprised two groups of forty HIV positive and HIV negative subjects respectively who were gotten by consecutive clinic recruitment and random sampling respectively. A structured questionnaire was used to retrieve the sociodemographic data after obtaining informed consent from willing participants. Blood samples were collected aseptically into ethylenediaminetetraacetic acid (EDTA) vacutainer bottles and later analyzed by atomic absorption spectrophotometry (AAS). Data analyses were carried out using data analysis software Epilnfo 7 and Microsoft Word Excel 2007. Results were presented as mean \pm standard deviation and the student t- test was used to compare means with significance set at $P \leq 0.05$. Findings included, instructively, a mean plasma selenium $(\mu \mathrm{g} / \mathrm{dl})$ of $0.0052 \pm 0.0024$ and $0.0223 \pm 0.0054$ among HIV negative and positive subjects respectively $(p<0.00001)$. This was in contradistinction to plasma zinc levels where in mean plasma levels $(\mu \mathrm{g} / \mathrm{dl})$ were $122.620 \pm 8.571$ and $83.35 \pm 5.49$ for HIV negative and positive subjectsrespectively $(p<0.00001)$. This may be a pointer to the need for supplementation of certain micronutrients during treatment of HIV infection, as had been noted in some other studies.
\end{abstract}

Keywords: Selenium, zinc, HIV and HIV negative

\section{INTRODUCTION}

The pandemic (UNAIDS 2009) scourge, HIV infection, is still without a cure and research is still ongoing for cure or possible discovery that would aid understanding the course, alleviate the disease /complications.Micronutrients are known to be important in the human body (Kim et al., 2005) and amongst other functions, are essential for maintaining proper immunologic function (Scrimshaw and San Giovanni1997). Studies have shown that folic acid deficiency depresses the cell-mediated immunity response (Gross et al., 1975),zinc deficiency decreases lymphocyte concentrations (Fraker et al., 2000), copper deficiency reduces the cytokine response (Percival,
1998) and selenium is needed for proper functioning of neutrophils and $\mathrm{T}$ lymphocytes (Ferencik and Ebringer 2003). Micronutrient deficiencies are associated with HIV1 disease progression and raise the possibility that normalization might increase symptom-free survival (Baum et al., 1995).Zinc(Zn) deficiency is usually due to insufficient dietary intake, but can be associated with malab sorption, acrodermatitis enteropathica, chronic liver disease, chronic renal disease, sickle cell disease, diabetes, malignancy, and other chronic illnesses (to which HIV infection is one). Symptoms of mild zinc deficiency are diverse. Clinical outcomes include depressed growth, diarrhea, impotence and delayed 
sexual maturation, alopecia, eye and skin lesions, impaired appetite, altered cognition, impaired host defense properties, defects in carbohydrate utilization, and reproductive teratogenesis (Prasad 2008).Selenium (Se)deficiency is rare in healthy, well-nourished individuals. It can occur in patients with severely compromised intestinal function, those undergoing total parenteral nutrition, and on advanced-aged people (over 90) (Ravaglia, 2000). Also, people dependent on food grown from selenium-deficient soil are at risk. Selenium deficiency may only occur when a low selenium status is linked with an additional stress, such as chemical exposure or increased oxidant stress due to vitamin $E$ deficiency (Mann 2002). Thisstudy was to evaluate the plasma levels of two micronutrients ( $Z n \&$ Se) which have been shown to play roles in immune function, in HIV infected and non-infected subjects to observe, if any, differences between these groups of individuals. In addition we sought to evaluate any correlations in these plasma levels vis a vis demographic factorsin both subject groups.

\section{RESEARCH DESIGN AND METHODS}

The comparative cross sectional study comprised 2 groups; 40 HIV positive subjects and 40 HIV negative subjects. The HIV positive subjects were drawn from patients attending the Special Treatment Centre (STC) in the hospital ( University of Abuja Teaching Hospital ) and were recruited consecutively during clinic sessions until the sample size was gotten. The HIV negative subjects control were recruited from the workforce within the university and the hospital. Subjects were informed of the purpose of the study and that there were no known risks associated with the study other than drawing of blood. And an informed consent was obtained from all the participants.An ethical clearance letter was obtained from the ethical review committee of the hospital.

\section{MATERIALS}

Stadiometer, $5 \mathrm{ml}$ syringes, cotton wool, methylated spirit, toniquet, vacutainers, block digester, dispenser, digestion tube, diluter, fume hood, heating system, centrifuge and Atomic absorption spectroscopy (AAS BUK 205)

\section{Reagents}

Concentrated sulphuric acid, 10\% Glycerine, 10\% Trichloro acetic acid(TCA), 20\% Trichloro acetic acid(TCA), 30\% Hydrogen peroxide, $0.1 \%$ Lanthanum chloride solution, Perchloric acid with nitric acid, Sulphuric acid with hydrogen peroxide, Triacid mixture of sulphuric, percloric and nitric acids(1.5:2:3).

\section{Procedure}

To both groups were administered questionnaires by the researcher and an assistant to retrieve the sociodemographic data. The weight and height of all the subjects were taken with the use of the stadiometer. The subjects were venipunctured aseptically with the help of a syringe and cotton swab and blood collected and stored in a vacutainer bottle (EDTA container) for laboratory use. The blood samples were centrifuged at 5000rpm, and plasma collected using a Pasteur pippetes to empty plasma into clean containers. One $\mathrm{ml}$ of serum was deproteinated with $9 \mathrm{ml}$ of $10 \%$ trichloroacetic acid (TCA) in $0.1 \%$ lanthanum solution for macroelement analysis.

Diluted was the resulting supernatant with $0.11 \%$ lanthanum which depended on concentration of individual elements and aspirated to the atomic absorption spectrophotometer. Label and refrigerate the remaining serum sample for determination of microelements.

\section{Determination of selenium}

Standard and blank were prepared by diluting plasma with $5 \%$ glycerine and read in AAS. Plasma was diluted $1: 4$ with water and read at wavelength of $423.5 \mathrm{~nm}$.

\section{Determination of zinc}

Standard and blank were prepared by diluting plasma with $5 \%$ glycerine and read in AAS. Plasma was diluted $1: 4$ with water, aspirated into the AAS and read at wavelength $213.9 \mathrm{~nm}$.

\section{Calculations}

Concentration of the elements in $\mu \mathrm{g} / \mathrm{dl}$ was calculated using the formular:

$\mathrm{Mg} / \mathrm{l}=\mathrm{ppm}=\mathrm{R} \times \mathrm{D}$

Where $\mathrm{R}=\mathrm{AAS}$ reading

$D=$ diluting factor

ppm $=$ parts per million.

\section{Caution}

The perchloric acid digestion must be carried out in a special hood designed to expel perchloric acid fumes to avoid the danger of explosion when in contact with organic matter. The acid also easily corrodes ordinary hoods.

\section{Data analysis}

Data analysis was carried out using Epi Info 7 and Microsoft Excel 2007.The results were presented as mean \pm standard deviation and the student t- test was used to compare means with significant $p$ value at $\mathrm{p} \leq 0.05$. 
Table 1.Tabular representation showing duration of illness of HIV positive subjects that were married.

\begin{tabular}{llll}
\hline S/N & $\begin{array}{l}\text { DURATION OF ILLNESS } \\
\text { (months) }\end{array}$ & Frequency & Percent \\
\hline 1 & 3 & 1 & 3.57 \\
2 & 7 & 1 & 3.57 \\
3 & 12 & 1 & 3.57 \\
4 & 36 & 3 & 10.71 \\
5 & 60 & 2 & 7.14 \\
6 & 72 & 8 & 28.57 \\
7 & 84 & 4 & 14.29 \\
8 & 96 & 4 & 14.29 \\
9 & 108 & 1 & 3.57 \\
10 & 132 & 1 & 3.57 \\
11 & 156 & 1 & 3.57 \\
12 & 180 & 1 & 3.57 \\
\hline
\end{tabular}

Table 2. Tabular representation showing duration illness of HIV positive subjects that were single.

\begin{tabular}{llll}
\hline & $\begin{array}{l}\text { DURATION OF ILLNESS } \\
\text { (months) }\end{array}$ & Frequency & Percent \\
S/N & & & \\
\hline 1 & 12 & 1 & 16.67 \\
2 & 24 & 1 & 16.67 \\
3 & 36 & 2 & 33.33 \\
4 & 84 & 1 & 16.67 \\
5 & 96 & 1 & 16.67 \\
\hline
\end{tabular}

Table 3. Tabular representation showing duration illness of HIV positive subjects that were widowed.

\begin{tabular}{llll}
\hline S/N & $\begin{array}{l}\text { DURATIONOFILLNESS } \\
\text { (months) }\end{array}$ & Frequency & Percent \\
\hline 1 & 48 & 1 & $33.33 \%$ \\
2 & 72 & 1 & $33.33 \%$ \\
3 & 84 & 1 & $33.33 \%$ \\
\hline
\end{tabular}

\section{RESULTS}

\section{Sociodemographic data}

Of the 80 subjects in both groups, $37(46.25 \%)$ were females and $43(53.75 \%)$ were males. The male sex contributed $25(58.14 \%)$ HIV negative males and $18(41.86 \%)$ HIV positive males. While the female sex contributed 22(59.46\%) positive females and 15(40.54\%) negative females. From the HIV positive study group, $28(70.00 \%)$ were married, $7(17.50 \%)$ were single, $3(7.50 \%)$ were widowed and $2(5.00 \%)$ were divorced. The marital status for hiv negative subjects were
$25(62.50 \%)$ married and $15(37.50 \%)$ single. Of both groups $30(68.18 \%)$ were negative civil servants and $14(31.82 \%)$ were positive civil servants. Also in the study, the students contributed $8(61.54 \%)$ HIV negative and $5(38.46 \%)$ HIV positive. The self employed in the study were 20(90.91\%) HIV positive subjects and 2(9.09) HIV negative subjects. The age distribution of HIV negative subjects showed between the ages of $21-30$ to be 14 were, between the ages $31-40$ to be 12 , between the ages of 41-50 were 10 and 4 were between the ages of 51-60. While the age distribution for HIV positive subjects showed, between the ages of 31-40 years to be 13 subjects, between the ages of 41-50 years were 10, 
Table 4. Tabular representation showing duration illness of HIV positive subjects that were divorced

\begin{tabular}{lll}
\hline $\begin{array}{l}\text { DURATIONOFILLNESS } \\
\text { (months) }\end{array}$ & Frequency & Percent \\
\hline 5 & 1 & $50.00 \%$ \\
24 & 1 & $50.00 \%$ \\
\hline
\end{tabular}

Table 5. Plasma selenium and zinc in HIV negative and HIV positive subjects.

\begin{tabular}{|l|l|l|l|l|}
\hline \multirow{2}{*}{} & \multirow{2}{*}{ ELEMENT } & \multicolumn{2}{|l|}{ MEAN \pm STANDARD DEVIATION } & \multirow{2}{*}{ P-VALUE } \\
\cline { 3 - 5 } & & NEGATIVE & POSITIVE & \\
\hline 1. & Selenium & $0.0052 \pm 0.0024$ & $0.0223 \pm 0.0054$ & $<0.00001$ \\
\hline 2. & Zinc & $122.620 \pm 8.571$ & $83.35 \pm 5.49$ & $<0.00001$ \\
\hline
\end{tabular}

between 21-30 years were 8 , between $51-60$ years were 7 and 2 were less than 20 years of age.

\section{Duration of illness for hiv positive subjects}

\section{Comparison of selenium and zinc}

\section{DISCUSSION}

The results showed that more females were infected with the HIV than males but this is probably predicated on the fact that the HIV positive subjects were gottenby consecutive clinic recruitment from the HIV special centre in the University of Abuja Teaching Hospital Gwagwalada Abuja where females have been shown to seek care more than males. This female prepondrance in HIV infection is consistent with a study in Zaria, Kaduna State, Nigeria (Laah, 2003) and the publication by UNAIDS 2002 at Geneva.This result is however contradictory to Giri et al., 1995 study in Northern India and Cheong et al., 1997 in Kuala Lumpur, Malaysia. However suffice to state that reasons have been adduced for the relatively higher proportion of women with HIV infection such as polygamy, low literacy level, practice of female genital mutilation (FGM), other harmful cultural practices, early age at first sex of adolescent girls, many sex partners as seen in commercial sex workers and the fact that, a higher proportion of men $(30 \%)$ than women $(19 \%)$ in less developed countries have comprehensive knowledge of HIV and how to avoid transmission (Bremner et al., 2009). The sex distribution of the HIV negative subjects would be inconsequential because the HIV negative subjects were from friends, neighbours, and other willing volunteers with already ascertained HIV status.In terms of age distribution for the HIV positive subjects, the age group between 31-40 and 41-50 had the highest percentages (32.5 and $25 \%$ respectively) of infected individuals, this agrees with similar work done by HIV survellance team of the United state of America Center for Diseases and Control(CDC, 2009) and other researchers (NYSC, 2007) in Abuja, Nigeria.The high percentages $32.5 \%$ and $20.0 \%$ noticed in $31-40$ and 21 30 years age groups is consistent with some studies in Nigeria (Laah, 2003; Mamman, 2009 and NYSC/UNICEF, 2007). These age groups are also characterized by social vices such as, unwanted pregnancy, unsafe abortions, drug use and sexually transmitted infections(Laah, 2003). The marital status shows that from the HIV positive study group, $28(70.00 \%)$ were married, $7(17.50 \%)$ were single, $3(7.50 \%)$ were widowed and $2(5.00 \%)$ were divorced. This high percentage of HIV positive being married was seen in the over $60 \%$ HIV positive individuals noticed in the report of Federal Ministry of Health, 2008 in Nigeria. This worrisome finding could be attributed to polygamy often practiced in Nigeria, but in no way excludes poor knowledge of the disease, un-protective sex, multiple sexual partners, blood transfusion, harmful cultural practices and patronage of commercial sex workers. The result of this study which showed $14(31.82 \%)$ civil servants HIV positive, $5(38.46 \%)$ students were HIV positive and $20(90.91 \%)$ HIV positive subjects selfemployed was not at par with lower percentages of $18.2 \%$ and $8.5 \%$ noticed in civil servants and students in UNAIDS report, 2008.

The mean plasma selenium in $\mu \mathrm{g} / \mathrm{dl}$ of HIV negative and positive subjects were $0.0052 \pm 0.0024$ and 0.0223 \pm 0.0054 respectively with a $p$-value of $<0.00001$ (Table 5 ) showing the difference was significant. The HIV positive subjects had higher levels of Se than the HIV negative subjects. This result is similar to Khalili et al., 2011 but in contrast with research works conducted by Fawzi, 2003,Kiremidjian et al 2003 and Zhang et al., 1999 where HIV positive subjects had lower levels of 
Nwegbu et al. 257

Table 6. Plasma selenium and zinc in males and females that are HIV positive.

\begin{tabular}{|l|l|l|l|l|}
\hline \multirow{2}{*}{} & \multirow{2}{*}{ ELEMENT } & \multicolumn{2}{|l|}{ MEAN \pm STANDARD DEVIATION } & \multirow{2}{*}{ P-VALUE } \\
\cline { 3 - 4 } & & FEMALES & MALES & \\
\hline 1. & Selenium & $0.00221 \pm 0.0058$ & $0.0219 \pm 0.0046$ & $<0.009$ \\
\hline 2. & Zinc & $85.168 \pm 4.3626$ & $81.399 \pm 6.186$ & $<0.032$ \\
\hline
\end{tabular}

Table 7. Plasma selenium and zinc in males and females that are HIV negative.

\begin{tabular}{|l|l|l|l|l|}
\hline \multirow{2}{*}{} & \multirow{2}{*}{ ELEMENT } & \multicolumn{2}{|l|}{ MEAN \pm STANDARD DEVIATION } & \multirow{2}{*}{ P-VALUE } \\
\cline { 3 - 5 } & & FEMALES & MALES & \\
\hline 1. & Selenium & $0.0061 \pm 0.0074$ & $0.0055 \pm 0.0024$ & $<0.00001$ \\
\hline 2. & Zinc & $109.17 \pm 9.780$ & $113.67 \pm 9.89$ & 0.0012 \\
\hline
\end{tabular}

selenium. Recent research indicates that HIV may be capable of incorporating host selenium into viral selenoproteins that have glutathione peroxidase activity (Zhang et al., 1999) but as an integral component of glutathione peroxidase and thioredoxin reductase, selenium plays an important role in decreasing oxidative stress in HIV-infected cells possibly suppressing the rate of HIV replication (Kiremidjian-Schumacher et al., 2000). Therefore the fact that "decreasing plasma selenium concentrations in HIV-infected individuals are sensitive markers of disease progression and severity", even before malnutrition becomes a factor (Fawzi, 2003) and Low levels of plasma selenium been associated with a significantly increased risk of death from HIV infection, would indicate our study caught HIV subjects that were in the state of early course (low severity)of the infection thus their high level of Se or as a result of the supplementary micronutrient taken by the HIV subjects. HIV positive females had significantly lower levels of Se than the males since the plasma selenium $(\mu \mathrm{g} / \mathrm{dl})$ in HIV positive females and males were $0.00221 \pm 0.0058$ and $0.0219 \pm$ 0.0046 respectively and the $\mathrm{P}$-value $<0.009$ (Table 6).

There was a statistically significant $(P<0.00001)$ difference between mean plasma zinc in $\mu \mathrm{g} / \mathrm{dl}$ in HIV negative and positive subjects $122.620 \pm 8.571$ and $83.35 \pm 5.49$ respectively (table 5 ) showing the HIV negative subjects with higher levels of $Z n$ relative to HIV positive subjects which was similar to values seen in research by Gadallah, 2000. Zn is essential for maintaining immune system function, and in the presence of oxidative stress, without a corresponding increase in supply $\mathrm{Zn}$ level there would result a deficiency. This possibly explains the reduced plasma levels of $\mathrm{Zn}$ in the HIV positive subjects. Decreased plasma zinc concentrations have been associated with advanced disease and increased mortality in HIV patients (Mocchegiani and Muzzioli, 2000).HIV positive females had higher levels of $\mathrm{Zn}$ than their male counterparts which was significant in this study $(P<0.03)($ table 6$)$. This is similar to results obtained by Milbury and Richer, 2008, though the higher number of female HIV subjects in our study could have skewed our findings in this regard.

In conclusion, our study findings highlight the need for assessment of micronutrient status of relevant elements with proven immunological functions in HIV infected people and correction of deficiencies where observed. It is also important to assess and document any nutritional supplements being taken by these patients, by their respective physicians. This will assist in proper evaluation and interpretation of research findings involving micronutrients in this group of patients. This latter observation was a limitation in this study and further studies taking this into cognizance as well as with larger sample sizes are needed to clarify the myriad and sometimes contrasting findings in this area of research.

\section{ACKNOWLEDGEMENT}

The authors will like to acknowledge the assistance of $\mathrm{Mr}$ Basil of International Institute of Tropical Agriculture (IITA) Ibadan in the analysis of the elements.

\section{REFERENCES}

Baum MK, Shor-Posner G, Lu Y, Rosner B, Sauberlich HE, Fletcher MA, Szapocznik J, Eisdorfer C, Buring JE, Hennekens $\mathrm{CH}$ (1995).Micronutrients and HIV-1 disease progression.AIDS. 1995 Sep;9(9):1051-6.

Bremner J, C Haub, M Lee, M Mather, E Zuehlke(2009) World population highlights: Key findings from PRB's world population data sheet. Popul.Bull; 2009; 64(3): 2-12.

Center for Disease Control(CDC) Diagnosis of HIV infection and AIDS in the United States and Dependent Areas; HIV Surveillance ; 2009 Report-Vol. 21.

Cheong I, A Lim, C Lee, Z Ibrahim, K Sarvanathan (1997) Epidemiology and clinical characteristics of HIV-infected patients in Kuala Lumpur. Med. J. Malays; 52: 313-317. 
Fawzi W (2003). Micronutrients and HIV type-1 disease progression among adults and children.Clin. Infect. Dis. 37 (Suppl 2): 112-116.

Ferencik M, Ebringer $L(2003)$ Modulatory effects of selenium and zinc on the immune system.Folia Microbiol;48:417-26.

Fraker PJ, King LE, Laakko T, Vollmer TL(2000). The dynamic link between the integrity of the immune system and zinc status. J Nutr.130(suppl):1399S-406S

Giri TK, JP Wali, HS Meena, I Pande, S Uppal, S Kailashi (1995) Socio demographic characteristics of HIV infection in Northern India. J. Comm. Dis., 1995; 127(1): 1-9.

Gross RL, Reid JV, Newberne PM, Burgess B, Marston R, Hift W(1975). Depressed cell-mediated immunity in megaloblastic anemia due to folic acid deficiency. Am J Clin.Nutr;28:225-32

Khalili H, lan K, Bryan $\mathrm{M}(2011)$ Department of Pharmacotherapy, School of Pharmacy, Tehran University of Medical Sciences, Tehran, Iran.

Kim EB, Susan M, Scot B, Heddwen B(2005). In :Ganong review of Medical physiology $22^{\text {nd }}$ Ed United States longer.

Kiremidjian-Schumacher L, Roy M, Glickman R (2000).Selenium and immunocompetence in patients with head and neck cancer. Biol. Trace Elem. Res. 73(2): 97-111.

Laah JG(2003) The prevalence of HIVIAIDS in Zaria, Kaduna State. J. Popul. Assoc. Nigeria. 3(1): 95-101.

Mamman M (2003) Gender HIV-infection and AIDS - Related deaths in sub-Saharan Africa. J. Popul. Assoc. Nigeria, 3(1): 79-94.

Mann Jim, Truswell A(2002) Stewart.Essentials of human nutrition (2nd ed.). Oxford universitypress. 2002; isbn 9780192627568

Milbury PE, Richer AC(2008) Understanding the Antioxidant Controversy: Scrutinizing the "fountain of Youth".Greenwood Publishing Group.p. 99.ISBN 0275993760.

Mocchegiani E, Muzzioli M (2000). Therapeutic application of zinc in human immunodeficiency virus against opportunistic infections.J.Nutr. 130(Suppl 5): 1424-1431.
National Youth Service Corps/UNICEF, National baseline survey on knowledge, attitudes, beliefs and practices on RH and HIVIAIDS. NYSC, Abuja. 2007.

Percival SS. Copper and immunity.Am J ClinNutr1998;67(suppl): 1064S-8S.

Prasad A.S. "zinc in human health: effect of zinc on immune cells". mol. med 2008.14 (5-6): 353-7:10.

Ravaglia Forti P, Maioli F, Bastagli I, Facchini A, Mariani E, Savarino I, Sassi S(2000) "Effect of micronutrient status on natural killer cell immune function in healthy free-living subjects aged >=90 y1". American j. of clinical nutrition71 (2): 1 february 2000. 590-598.

Scrimshaw NS, San Giovanni JP((1997) Synergism of nutrition, infection, and immunity: an overview. Am J ClinNutr 1997, 66(suppl):464S-77S

UNAIDS 2002 Geneva; AIDS Epidemic. p. 6.

UNAIDS and World Health Organization AIDS Epidemic Update. Joint United Nations Programme on HIVIAIDS (UNAIDS), Geneva. Available online at http://data.unaids.org/pub/Report/2009/2009_ epidemic_update_en.pdf, 2009

Zhang W, Ramanathan CS, Nadimpalli RG, Bhat AA, Cox AG, Taylor EW (1999). Selenium-dependent glutathione peroxidase modules encoded by RNA viruses. Biol. Trace Elem. Res. 70 (2): 97-116. 